\title{
Comparison of bronchoalveolar lavage and catheter lavage to confirm ventilator-associated lower respiratory tract infection
}

\author{
H. HUMPHREYS, R. WINTER* ${ }^{*}$, M. BAKER ${ }^{\dagger}$ and C. SMITH* \\ Division of Microbiology, ${ }^{\dagger}$ Public Health Laboratory and *Adult Intensive Care Unit, University Hospital, \\ Queen's Medical Centre, Nottingham, NG7 2UH
}

\begin{abstract}
Lower respiratory tract infection (LRTI) is a well recognised complication of artificial ventilation in intensive care units (ICU). Ideally, specimens for microbiological analysis should be obtained during bronchoscopy, but this is not always possible. Therefore, the microbiological diagnosis of lower respiratory tract infection by broncho-alveolar lavage (BAL) obtained during bronchoscopy was compared with catheter lavage (CL) with a balloon-tipped catheter. Adult patients with clinical evidence of lower respiratory tract infection in an adult ICU were randomly assigned to undergo BAL followed by $\mathrm{CL}$ or vice versa. Forty $\mathrm{ml}$ of normal saline $0.9 \%$ were instilled and then aspirated with a flexible bronchoscope to obtain BAL. A similar volume was instilled and aspirated with a 12-gauge Foley balloon-tipped catheter to obtain a $C L$ sample. The number of inflammatory cells, epithelial cells and organisms seen by microscopy were quantified. Culture results were semi-quantified and classified as negative, positive, equivocal or contaminated. Seventy-nine paired specimens were obtained from 66 patients, including specimens from 10 patients taken on two or more occasions. Only $20 \%$ of BAL and $16 \%$ of CL had one or more epithelial cells and bacteria were seen in 26 BAL and 21 CL specimens, respectively; $35 \%$ of BAL and CL specimens were positive and there was a discrepancy in the culture result in only two cases. Staphylococcus aureus was the pathogen isolated most frequently and polymicrobial lower respiratory infection was diagnosed on 10 occasions (15\%). CL fluid is as reliable as BAL in diagnosing lower respiratory tract infection in ICU. This approach does not require bronchoscopic expertise and utilises convenient laboratory techniques.
\end{abstract}

\section{Introduction}

The increasing use of invasive techniques, tracheal intubation and mechanical ventilation in intensive care units (ICU) contributes to the risk of nosocomial infection, especially ventilator-associated lower respiratory tract infection (LRTI), including pneumonia. The incidence varies from 8 to 55 cases/100 ICU patients, with a median of 27 cases/100 patients [1] and various risk factors have been described [1-3]. This high incidence is accompanied by significant mortality, ranging from 26 to $71 \%[1,3]$. The extra cost attributable in 1992 to ventilator-associated pneumonia in one study was calculated to be $>$ US $\$ 8000 /$ patient [4].

Most cases of LRTI in the ICU are due to gramnegative bacilli such as Escherichia coli, other Enterobacteriaceae and Pseudomonas aeruginosa,

Received 20 Nov. 1995; accepted 8 Feb. 1996.

Corresponding author: Dr H. Humphreys. but Staphylococcus aureus is also important [5,6]. The usual causes are endogenous bacteria, including those colonising the stomach and oropharynx of the ICU patient [7,8]. Consequently, it is often difficult to distinguish colonising organisms from those causing infection.

A diagnosis of LRTI is usually made on the basis of clinical, radiological and microbiological evidence. The presence of fever, leucocytosis, increasing tracheobronchial secretions and the appearance of new infiltrates on chest radiography are some of the criteria used in diagnosis. However, these are nonspecific and may also be present following chest trauma, as part of the adult respiratory distress syndrome (ARDS) and during acute exacerbation of chronic bronchitis $[9,10]$. In a study of 69 patients, air bronchograms were predictive of pneumonia but radiology identified only $65 \%$ of cases of pneumonia diagnosed at autopsy [11]. Tracheal aspirates are commonly used in the diagnosis of pneumonia, but a more critical analysis of their usefulness indicates that they are less helpful and indeed may be 
misleading [12]. It is increasingly recommended that specimens such as protected brush specimens (PBS) or bronchoalveolar lavage (BAL) be obtained during bronchoscopy in ICU patients. Organisms recovered from such specimens are more likely to reflect pathology in the lung parenchyma, and quantification differentiates between specimen contamination during the procedure, colonisation of the airways and LRTI $[9,13,14]$.

Bronchoscopic diagnosis requires the ready availability of a flexible bronchoscope and considerable expertise. There is a need for easier, more accessible diagnostic approaches and this study compared the microbiological results of specimens obtained by BAL with those obtained by passing a balloon-tipped catheter via the endotracheal tube and obtaining catheter lavage (CL) specimens. Semi-quantitative microbiology was done on both specimens to determine how $\mathrm{CL}$ compared with BAL in diagnosing LRTI.

\section{Materials and methods}

\section{Patients and procedure}

The Adult Intensive Care Unit (AICU) at University Hospital has nine beds including one isolation cubicle. Approximately 650 patients are admitted annually, following multiple trauma, for organ support, for ventilation during respiratory infection or for postoperative care after major surgery. All patients are assessed on admission by the APACHE II score [15]. The AICU is staffed by five consultants with four resident junior staff and a consultant medical microbiologist visits the unit daily.

All patients were considered for BAL or CL when lower respiratory tract infection was suspected on the basis of two or more of the following criteria: two temperature spikes $>38.5^{\circ} \mathrm{C}$, white cell count $>12000$ or $<2500 \times 10^{9} / \mathrm{L}$, increased respiratory secretions, new infiltrates on chest X-ray, or an increase of 0.15 in the $\mathrm{FiO}_{2}$ to maintain arterial oxygen tension. Infection was considered community-acquired if present at or within $48 \mathrm{~h}$ of admission to hospital and hospital-acquired if diagnosed after this time [16]. Bronchoalveolar and catheter lavage were each performed on every patient in an order determined by selection of a randomly ordered card in a sealed envelope. During BAL, the flexible bronchoscope (Olympus BFIT20) was wedged in the radiologically affected zone and the midzone or lingula of the unaffected side, and washings of $40 \mathrm{ml}$ of normal saline $(0.9 \%)$ were instilled and subsequently aspirated. The balloon-tipped catheter was a 12-gauge Foley with the balloon pre-inflated with $10 \mathrm{ml}$ of air, which was then withdrawn. The catheter was then inserted blindly until wedged and the balloon was inflated gently with $2 \mathrm{ml}$ of air. Forty $\mathrm{ml}$ of normal saline $(0.9 \%)$ were instilled and then aspirated. All specimens were processed within $2 \mathrm{~h}$ of being taken or refrigerated. This study was started before the publication of consensus guidelines for bronchoscopy [17] and it was decided not to modify the protocol subsequently.

\section{Microbiological examination}

The volume of fluid received and the appearance of the specimen was recorded. Samples were inoculated with a standard loop $(5 \mu \mathrm{l})$ on to blood agar, chocolate (heated blood) agar, MacConkey agar and for anaerobic bacteria on to neomycin blood agar. Culture for legionellae, mycobacteria, fungi or viral pathogens was performed when clinically indicated, as was antigen detection by direct immunofluoresence for atypical causes of pneumonia such as Mycoplasma pneumoniae and Chlamydia spp., etc. Bronchoalveolar and catheter fluid was centrifuged for $5 \mathrm{~min}$ at $3000 \mathrm{rpm}$ and the sediment was Gram stained. The mean number of inflammatory cells (white cells, mainly polymorphonuclear neutrophils), organisms and epithelial cells seen in 15-20 high power fields (magnification $\times 1000$ ) was recorded for each specimen. The number of organisms isolated (expressed as $\mathrm{cfu} / \mathrm{ml}$ of lavage fluid) was semi-quantified and categorised into three groups: $>10^{5} \mathrm{cfu} / \mathrm{ml}, 10^{4} \mathrm{cfu} /$ $\mathrm{ml}$ or $<10^{4} \mathrm{cfu} / \mathrm{ml}$, by comparison with standard cultures [18]. The diagnosis of pneumonia and the interpretation of culture results for BAL and CL specimens were as described previously [19]. Briefly, specimens were considered positive if the number of pathogenic organisms was $>10^{5} \mathrm{cfu} / \mathrm{ml}$ or $10^{4} \mathrm{cfu} / \mathrm{ml}$ (pure growth only), negative if sterile or $<10^{4-5} \mathrm{cfu} /$ $\mathrm{ml}$, equivocal if there was a pure growth $10^{4-5} \mathrm{cfu} / \mathrm{ml}$ with inflammatory cells on microscopy and contaminated if $10^{4-5} \mathrm{cfu} / \mathrm{ml}$ without inflammatory cells or $\geqslant 10^{4-5} \mathrm{cfu} / \mathrm{ml}$ or greater but with more than one organism isolated and two or more epithelial cells seen per high power field.

\section{Statistical analysis}

All data were entered on to a spreadsheet (Quattro Pro, Borland, USA) and kappa, i.e., the proportion of potential agreement beyond chance that was actually achieved, was calculated [20]. Numerical kappa values of 0.6-0.8 show substantial agreement and 0.8-1.0 almost perfect agreement [20]. Further statistical analysis was performed with Minitab for Windows (Minitab Inc.), version 10 and paired non-parametric data were analysed by Wilcoxon with $\mathrm{p}$ values $<0.05$ considered significant.

\section{Results}

\section{Patient characteristics}

Seventy-nine paired specimens were received from 66 patients. The mean age was 53 years (range 15-87) and 
the male:female ratio was $37: 29$. Table 1 outlines the clinical characteristics of the patients, comparing those for whom BAL was performed first followed by $\mathrm{CL}$ and vice versa. The most common indication for admission to the AICU was respiratory failure (22 patients) followed by post-operative neurosurgical care (seven patients). There was no significant difference in APACHE II score on admission, duration of ventilation and whether respiratory infection was considered to be hospital- (41 patients) or community- (25 patients) acquired and the outcome was similar (i.e., death or discharge from the AICU) in the two groups whether BAL preceded or followed CL.

\section{$B A L$ and $C L$ microscopy}

BAL was obtained first on 35 occasions and followed $\mathrm{CL}$ on 41 occasions (for three pairs of specimens, the order was not stated). Patients were receiving antibiotics at the time of the procedure on six occasions $(18 \%)$ when BAL preceded CL and on 14 occasions $(36 \%)$ when CL was performed first. Paired specimens were received from 10 patients on two or more occasions. The mean BAL volume received for microbiological processing was $7.4 \mathrm{ml}$ compared with $7.9 \mathrm{ml}$ for CL. Volumes aspirated did not differ significantly according to the order in which the specimen was obtained. Fig. 1 and 2 outline the number of inflammatory and epithelial cells seen on Gram's stain. In only $16(20 \%)$ of BAL and $13(16 \%)$ of CL specimens was one or more epithelial cells seen. There was reasonable agreement between the two techniques in the detection of inflammatory (kappa, 0.44) and epithelial (kappa, 0.62) cells. Bacteria were seen on microscopy in $26 \mathrm{BAL}$ and $21 \mathrm{CL}$ specimens (kappa, $0.64)$ usually in low numbers, i.e., one-to-three bacteria per high power field (magnification $\times 1000$ ). Intracellular organisms were seen in four BAL and three CL specimens only.

\section{Culture results}

Forty-one (52\%) BAL and 44 (56\%) CL specimens gave negative culture results; $27(35 \%) \mathrm{BAL}$ and 28 $(35 \%)$ CL specimens gave positive results. Similar numbers of patients were receiving antibiotics in the culture-positive ( 8 of $28,29 \%$ ) and culture negative (17 of $51,33 \%$ ) groups. There was good agreement between the interpretation of BAL and CL specimens (kappa, 0.91, Table 2). The organisms isolated, the order of investigation and the outcome of patients with positive results are outlined in Table 3 . There was a discrepancy in culture results between $\mathrm{CL}$ and BAL specimens in two cases; in one, the positive $\mathrm{CL}$ specimen $\left(>10^{5} \mathrm{cfu} / \mathrm{ml}, P\right.$. aeruginosa) was obtained before the negative BAL $\left(<10^{4} \mathrm{cfu} / \mathrm{ml}, P\right.$. aeruginosa); this may be explained by a dilutional effect. In the other, this explanation is less likely as the first specimen gave a negative result $\left(\mathrm{CL},<10^{4} \mathrm{cfu} / \mathrm{ml}\right.$, Enterobacter cloacae) and the BAL, which followed, was positive $\left(10^{4-5} \mathrm{cfu} / \mathrm{ml}\right.$, E. cloacae $)$.

Polymicrobial infection was diagnosed on 10 occasions. S. aureus was isolated with gram-negative bacilli on six occasions and more than three pathogens were isolated on two occasions. One patient had pulmonary aspergillosis with underlying lymphoma. Mycobacterium kansasii was isolated from another patient. He died some weeks after discharge from AICU and post-mortem examination indicated that $M$. kansasii was a probable cause of chronic infection.

\section{Discussion}

The diagnosis of ventilator-associated LRTI, especially in the presence of ARDS, is often difficult and requires a combined clinical, radiological and microbiological approach. The combination of fever, an infiltrate on

Table 1. Demographic characteristics of the patients studied

\begin{tabular}{lcc}
\hline Characteristics & BAL first $(29)^{* \dagger}$ & CL first $(34)^{* \dagger}$ \\
\hline Mean age (years) & 49.6 & 55.6 \\
& $(19-81)$ & $(15-77)$ \\
Male: female & $14: 15$ & $19: 15$ \\
Reason for admission & 8 & 8 \\
$\quad$ Multiple trauma & 0 & 0 \\
Organ support & 5 & 2 \\
$\quad$ Neurosurgical & 7 & 14 \\
$\quad$ Respiratory failure & 9 & 10 \\
Other & 11.7 & 10.9 \\
Mean duration of ventilation (d) & 5 & 4 \\
Interval to procedure (d) & 12.8 & 14.1 \\
Mean APACHE II score on admission & $(2-25)$ & 21 \\
& 18 & 13 \\
Hospital-acquired LRTI & 11 & 24 \\
Community-acquired LRTI & 16 & 10 \\
Outcome & 13 & \\
$\quad$ Discharged from AICU & & \\
Death & & \\
* Where a patient was studied on more than one occasion, findings on the first occasion only are \\
included. \\
†Details of three patients, for whom the order is not known, are excluded.
\end{tabular}




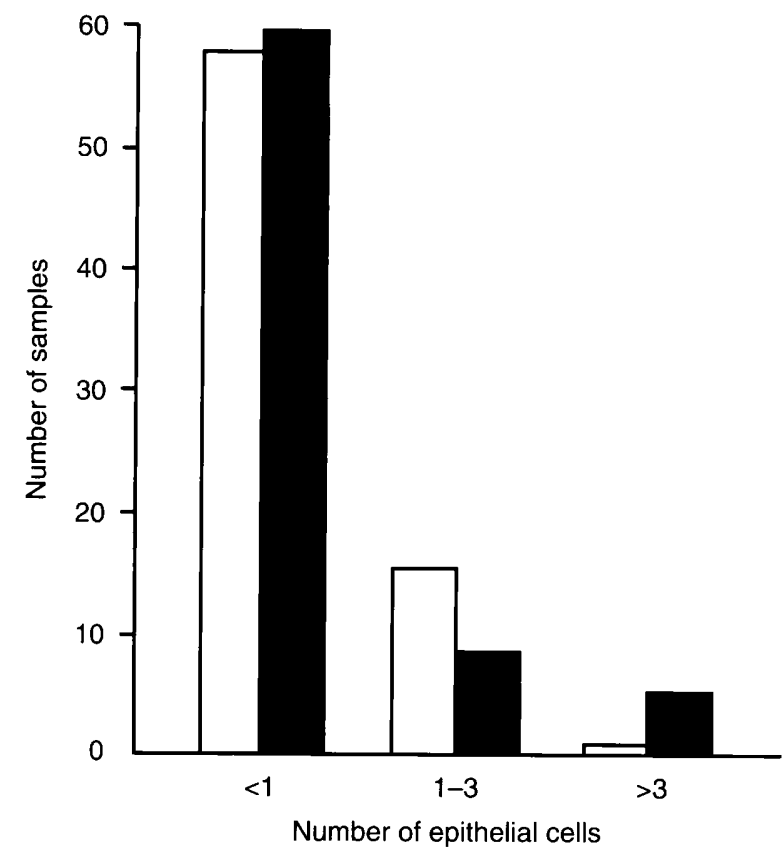

Fig. 1. Number of epithelial cells seen on microscopy

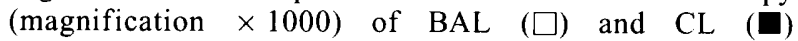
samples.

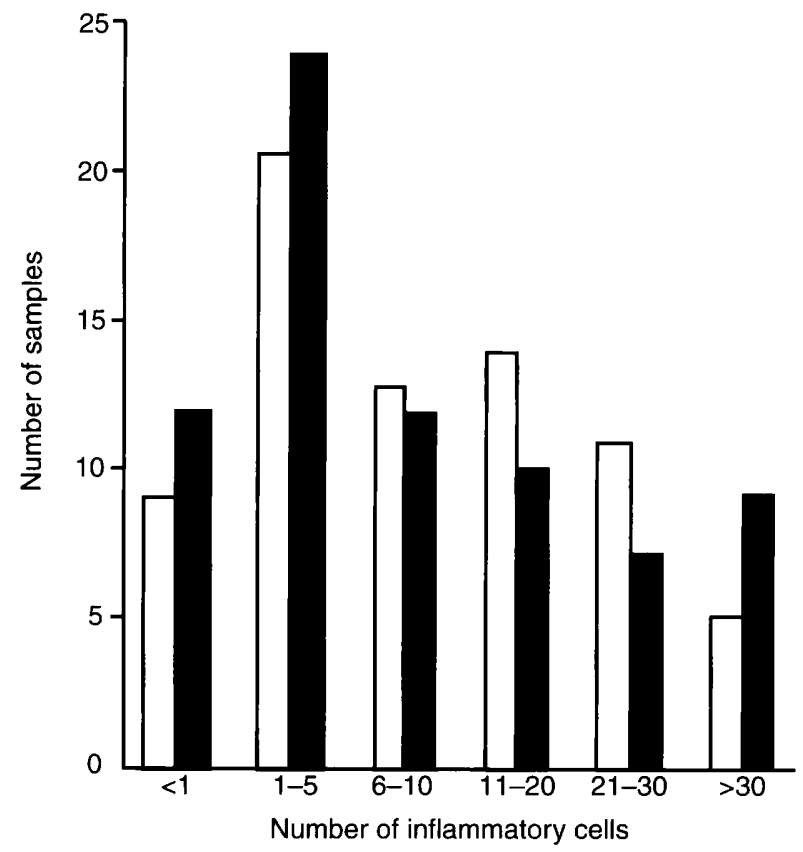

Fig. 2. Number of inflammatory cells seen on microscopy (magnification $\times 1000$ ) of BAL ( $\square$ ) and CL (G) samples.

chest X-ray and increased respiratory secretions may be explained by other causes. In a study of 84 patients suspected of having nosocomial pneumonia because of new pulmonary infiltrates on chest X-ray and purulent sputum, a clinical diagnosis was accurate in $62 \%$ of cases and therapy was inappropriate in two-thirds, especially for polymicrobial infection [10]. Bronchoscopic techniques are increasingly recommended to confirm a diagnosis microbiologically. PBS has undergone the most extensive evaluation but doubts remain about its specificity $[21,22]$. False negative results may occur in patients on antibiotics [21] but this also applies to BAL, which is the preferred technique in our hospital. Torres and colleagues compared BAL, bronchial aspirates, percutaneous lung needle aspirates (PLNA) and PBS with immediate histopathology of post-mortem lung biopsies and good correlation was found between PBS and BAL [22]. Because PBS and $\mathrm{BAL}$ require bronchoscopy, a fall in arterial $\mathrm{O}_{2}$ tensions, arrhythmias and fever may follow [21]. These complications, together with the unavailability of flexible bronchoscopes in some units and the requirement for an experienced bronchoscopist, have prompted a search for alternatives.

In this study, the laboratory techniques used were those available in most centres and it was designed to assess whether BAL and CL specimens were equivalent microbiologically in confirming a diagnosis of LRTI. A semi-quantitative technique was used rather than a spiral plater, which is not always available. These results suggest that non-bronchoscopic lavage, i.e., $\mathrm{CL}$, is a useful alternative to BAL. Volumes of fluid aspirated, the numbers of epithelial cells, inflammatory cells and bacteria seen on microscopy were similar and culture results were equivalent. Without histological analysis obtained either from lung biopsy or at autopsy, it is not possible to differentiate pneumonia from airways infection. The relatively small volume of fluid obtained for analysis was similar to that recorded by Meduri and colleagues, who received only $22 \%$ of the fluid instilled in ventilated patients by unprotected BAL and who could not distinguish pneumonia from bronchitis [23]. Since the start of this study, consensus guidelines on the techniques used, including sampling, microscopy and diagnostic thresholds, have been published [17]. The use of the May-Grünweld Giemsa stain for the evaluation of alveolar cell populations and discarding the first $20 \mathrm{ml}$ of BAL, both of which were not part of our protocol, are recommended. The detection of intracellular bacteria was not as useful a predictor of pneumonia as previously described [24] except for $S$. aureus, for which intracellular bacteria were seen on three occasions.

Gaussorgues and colleagues compared non-bronchoscopic lavage (NBL) with a cuffed re-usable catheter with open lung biopsy in 13 patients with pulmonary infiltrates who died in ICU [25]. Culture of NBL revealed the same organisms as lung biopsy in eight of nine patients with pneumonia, despite all patients receiving antibiotics for $\geqslant 4$ days beforehand. Another study compared BAL obtained by bronchoscopy with NBL in 40 samples from 28 patients, using a bacterial index to assess significance of the numbers of bacteria isolated [24]. Although BAL and NBL were obtained from all patients, this study differed from the present study in that BAL always preceded NBL. The number of bacteria isolated from specimens as expressed by the bacterial index was similar in both specimens, even where NBL was obtained from radiologically 
Table 2. Interpretation of BAL and CL specimens

\begin{tabular}{lccccr}
\hline & \multicolumn{3}{c}{ CL result } \\
\cline { 2 - 6 } BAL result & contaminated & negative & positive & equivocal & Total \\
\hline Contaminated & 4 & 2 & 0 & 0 & 6 \\
Negative & 0 & 40 & 1 & 0 & 41 \\
Positive & 0 & 1 & 26 & 0 & 27 \\
Equivocal & 0 & 44 & 28 & 3 & 79 \\
Total & 4 & & & 3 & 79 \\
\hline
\end{tabular}

kappa, 0.91 .

Table 3. Organisms isolated, order of procedure and outcome for culture-positive patients

\begin{tabular}{|c|c|c|c|}
\hline Organisms & Number of patients & Order of procedure & Outcome \\
\hline \multicolumn{4}{|l|}{ Gram-negative bacilli } \\
\hline Enterobacter spp. & 4 & $\begin{array}{l}\text { BAL 1st, 1 } \\
\text { CL 1st, 2 } \\
\text { Not known, 1 }\end{array}$ & $\begin{array}{l}\text { Discharged, } 3 \\
\text { Died in AICU, } 1\end{array}$ \\
\hline Haemophilus influenzae & 2 & $\begin{array}{l}\text { BAL 1st, } 1 \\
\text { CL 1st, } 1\end{array}$ & $\begin{array}{l}\text { Discharged, } 1 \\
\text { Died in AICU, } 1\end{array}$ \\
\hline Escherichia coli & 2 & $\begin{array}{l}\text { BAL 1st, } 1 \\
\text { CL 1st, } 1\end{array}$ & $\begin{array}{l}\text { Discharged, } 1 \\
\text { Died in AICU, } 1\end{array}$ \\
\hline Others & 3 & $\begin{array}{l}\text { BAL 1st, } 1 \\
\text { CL } 1 \text { st, } 2\end{array}$ & $\begin{array}{l}\text { Discharged, } 2 \\
\text { Died in AICU, } 1\end{array}$ \\
\hline S. aureus & 4 & $\begin{array}{l}\text { BAL 1st, } 3 \\
\text { CL 1st, } 1\end{array}$ & $\begin{array}{l}\text { Discharged, } 3 \\
\text { Died in AICU, } 1\end{array}$ \\
\hline Polymicrobial & 10 & $\begin{array}{l}\text { BAL Ist, } 5 \\
\text { CL 1st, } 5\end{array}$ & $\begin{array}{l}\text { Discharged, } 7 \\
\text { Died in AICU, } 3\end{array}$ \\
\hline Others & 3 & $\mathrm{CL} 1 \mathrm{st}, 3$ & $\begin{array}{l}\text { Discharged, } 2 \\
\text { Died in AICU, } 1\end{array}$ \\
\hline
\end{tabular}

unaffected lung [24]. Two further studies have assessed the usefulness of quantitative bacterial cultures of endotracheal aspirates (EA) and recorded a lower specificity for EA compared with BAL and PBS [26,27]. A negative EA culture result may exclude pulmonary infection but both studies recommend BAL or PBS unless unavailable [26, 27]. NBL has also been used to investigate the flora of distal airways during mechanical ventilation and to diagnose 65 episodes of pneumonia, in 20 of which BAL was also performed [28]. Concordant results between NBL and BAL were obtained in 16 of 20 episodes and the authors concluded that BAL was no better or accurate than NBL. The present study compared semi-quantitative bacterial cultures of BAL and CL and although there were minor differences in the number of squamous epithelial cells, inflammatory cells and organisms seen on microscopy and some differences in culture results, we believe that by taking sequential samples from the same patient, we have validated the use of NBL or $\mathrm{CL}$ as an alternative to BAL and confirmed the findings of Pugin and colleagues [24].

$S$. aureus was the most frequent pathogen isolated from our group of patients. In other studies, aerobic gram-negative bacilli, including Pseudomonas spp., have accounted for $40 \%$ of cases [1,29]. Staphylococcal pneumonia is described as being more common in neurosurgical patients [30] - a relatively large proportion of admissions to this unit. Acinetobacter spp. were responsible for LRTI in two patients and, as in other ICUs, this unit is experiencing increasing numbers of infections with this hospital pathogen. An epidemic of Acinetobacter infection occurred in the ICU during part of this study with over 35 patients becoming either colonised or infected [31].

We disagree with the reasons cited by some for not using either BAL, PBS or an appropriate alternative to diagnose nosocomial LRTI $[32,33]$ and recent reviews on the subject confirm our view $[34,35]$. Whilst there is some disagreement about the quantitative criteria used to distinguish infection from colonisation, we do not believe that concern about the safety of a cytocentrifuge [32] represents a contra-indication to these diagnostic techniques. In the present study, a simple, cheap and convenient approach to confirming a diagnosis of ventilator-associated LRTI was used. The development and validation of a new catheter for obtaining lavage specimens without the need for bronchoscopy [36] and the application of new guidelines [17] may facilitate accurate diagnosis. When a non-infectious cause of pulmonary infiltrates and fever such as tumour or haemorrhage is considered likely, especially in immunocompromised patients, bronchoscopy is preferred to inspect the bronchial tree with the option of obtaining tissue for histological analysis.

We thank all the staff of the Nottingham Public Health Laboratory and adult ICU for their help and co-operation during the conduct of this study.

\section{References}

1. George DL. Epidemiology of nosocomial ventilator-associated pneumonia. Infect Control Hosp Epidemiol 1993; 14: 163-169.

2. Joshi N, Localio AR, Hamory BH. A predictive risk index for 
nosocomial pneumonia in the intensive care unit. $\mathrm{Am} J \mathrm{Med}$ 1992; 93: 135-142.

3. Craven DE, Kunches LM, Kilinsky V, Lichtenberg DA, Make BJ, McCabe WR. Risk factors for pneumonia and fatality in patients receiving continuous mechanical ventilation. $A m R e v$ Respir Dis 1986; 133: 792-796.

4. Kappstein I, Schulgen G, Beyer U, Geiger K, Schumacher M, Daschner FD. Prolongation of hospital stay and extra costs due to ventilator-associated pneumonia in an intensive care unit. Eur J Clin Microbiol Infect Dis 1992; 11: 504-508.

5. Reusser P, Zimmerli W, Scheidegger D, Marbet GA, Buser M, Gyr K. Role of gastric colonization in nosocomial infections and endotoxemia: a prospective study in neurosurgical patients on mechanical ventilation. J Infect Dis 1989; 160: 414-421.

6. Inglis TJJ, Sproat LJ, Hawkey PM, Gibson JS. Staphylococcal pneumonia in ventilated patients: a twelve-month review of cases in an intensive care unit. $J$ Hosp Infect 1993; 25: $207-$ 210

7. Inglis TJJ, Sherratt MJ, Sproat LJ, Gibson JS, Hawkey PM. Gastroduodenal dysfunction and bacterial colonisation of the ventilated lung. Lancet 1993; 341: 911-913.

8. Millership SE, Patel N, Chattopadhyay B. The colonization of patients in an intensive treatment unit with gram-negative flora: the significance of the oral route. $J$ Hosp Infect 1986; 7 226-235.

9. Torres A, González J, Ferrer M. Evaluation of the available invasive and non-invasive techniques for diagnosing nosocomial pneumonias in mechanically ventilated patients. Intensive Care Med 1991; 17: 439-448.

10. Fagon J-Y, Chastre J, Hance AJ, Domart Y, Trouillet J-L, Gibert C. Evaluation of clinical judgement in the identification and treatment of nosocomial pneumonia in ventilated patients. Chest 1993; 103: 547-553.

11. Wunderink RG, Woldenberg LS, Zeiss J, Day CM, Ciemons J, Lacher DA. The radiologic diagnosis of autopsy-proven ventilator-associated pneumonia. Chest 1992; 101: 458-463.

12. Morris AJ, Tanner DC, Reller LB. Rejection criteria for endotracheal aspirates from adults. $J$ Clin Microbiol 1993; 31 $1027-1029$

13. Lode $H$, Schaberg $T$, Raffenberg $M$, Mauch $H$. Diagnostic problems in lower respiratory tract infections. $J$ Antimicrob Chemother 1993; 32 Suppl A: 29-37.

14. Faling LJ. New advances in diagnosing nosocomial pneumonia in intubated patients. Part I. Am Rev Respir Dis 1988; 137: 253-255

15. Knaus WA, Draper EA, Wagner DP, Zimmerman JE. APACHE II: a severity of disease classification system. Crit Care Med 1985; 13: 818-829.

16. National prevalence survey of hospital acquired infections: definitions. A preliminary report of the Steering Group of the Second National Prevalence Survey. J Hosp Infect 1993; 24: 69-76.

17. Meduri GU, Chastre J. The standardization of bronchoscopic techniques for ventilator-associated pneumonia. Chest 1992 102 Suppl 1: $557 \mathrm{~S}-564 \mathrm{~S}$.

18. Booth L, Lowes JA. Bacteriology of the respiratory tract. In: Hawkey PM, Lewis DA (eds) Medical bacteriology: a practical approach. Oxford, IRL Press. 1989: 43-69.

19. Winter R, Humphreys H, Pick A, MacGowan AP, Willatts SM Speller DCE. A controlled trial of selective decontamination of the digestive tract in intensive care and its effect on nosocomial infection. $J$ Antimicrob Chemother 1992; 30:
$73-87$.

20. Sackett DL, Haynes RB, Guyatt GH, Tugwell P. Clinical epidemiology. A basic science for clinical medicine, 2nd edn. Boston, Little Brown and Company. 1991: 30-31.

21. Meduri GU. Diagnosis of ventilator-associated pneumonia. Infect Dis Clin North Am 1993; 7: 295-329.

22. Torres A, el-Ebiary M, Padró $\mathrm{L}$ et al. Validation of different techniques for the diagnosis of ventilator-associated pneumonia. Comparison with immediate postmortem pulmonary biopsy. Am J Resp Crit Care Med 1994; 149: 324-331.

23. Meduri GU, Beals DH, Maijub AG, Baselski V. Protected bronchoalveolar lavage. A new bronchoscopic technique to retrieve uncontaminated distal airway secretions. Am Rev Respir Dis 1991; 143: 855-864.

24. Pugin J, Auckenthaler R, Mili N, Janssens J-P, Lew PD, Suter PM. Diagnosis of ventilator-associated pneumonia by bacteriologic analysis of bronchoscopic and nonbronchoscopic 'blind' bronchoalveolar lavage fluid. Am Rev Respir Dis 1991; 143: 1121-1129.

25. Gaussorgues P, Piperno D, Bachmann $\mathrm{P}$ et al. Comparison of nonbronchoscopic bronchoalveolar lavage to open lung biopsy for the bacteriologic diagnosis of pulmonary infections in mechanically ventilated patients. Intensive Care Med 1989; 15 94-98.

26. Marquette $\mathrm{CH}$, Georges $\mathrm{H}$, Wallet $\mathrm{F}$ et al. Diagnostic efficiency of endotracheal aspirates with quantitative bacterial cultures in intubated patients with suspected pneumonia. Comparison with the protected specimen brush. Am Rev Respir Dis 1993; 148: 138-144.

27. el-Ebiary M, Torres A, González J et al. Quantitative cultures of endotracheal aspirates for the diagnosis of ventilatorassociated pneumonia. Am Rev Respir Dis 1993; 148: 15521557.

28. A'Court CHD, Garrad CS, Crook D et al. Microbiological lung surveillance in mechanically ventilated patients, using nondirected bronchial lavage and quantitative culture. $Q J \mathrm{Med}$ 1993; 86: 635-648.

29. Prod'hom G, Leuenberger $\mathrm{P}$, Koerfer $\mathrm{J}$ et al. Nosocomial pneumonia in mechanically ventilated patients receiving antacid, ranitidine, or sulcrafate as prophylaxis for stress ulcer. A randomized controlled trial. Ann Intern Med 1994; 120: 653-662.

30. Espersen F, Gabrielsen J. Pneumonia due to Staphylococcus aureus during mechanical ventilation. $J$ Infect Dis 1981; 144: 19-23.

31. Crowe M, Towner KJ, Humphreys H. Clinical and epidemiological features of an outbreak of acinetobacter infection in an intensive therapy unit. $J$ Med Microbiol 1995; 43: 55-62.

32. Inglis $T$. The role of the laboratory in the diagnosis of nosocomial pneumonia. Intensive Care World 1993; 10: 120121 .

33. Niederman MS, Torres A, Summer W. Invasive diagnostic testing is not needed routinely to manage suspected ventilatorassociated pneumonia. Am Rev J Respir Crit Care Med 1994; 150: $565-569$.

34. Chastre J, Fagon JY. Invasive diagnostic testing should be routinely used to manage ventilated patients with suspected pneumonia. Am J Respir Crit Care Med 1994; 150: 570-574.

35. Baselski VS, Wunderink RG. Bronchoscopic diagnosis of pneumonia. Clin Microbiol Rev 1994; 7: 533-558.

36. Levy H. Comparison of Ballard BAL catheter with bronchoscopic broncho-alveolar lavage. Chest 1992; 102 Suppl: 143S 